\title{
Transient vehicle handling analysis with aerodynamic interactions
}

\author{
K Hussain $^{1 *}$, H Rahnejat ${ }^{2}$, and S Hegazy ${ }^{1}$ \\ ${ }^{1}$ School of Engineering, Design and Technology, University of Bradford, Bradford, UK \\ ${ }^{2}$ Wolfson School of Mechanical and Manufacturing Engineering, Loughborough University, Loughborough, UK
}

The manuscript was received on 18 January 2006 and was accepted after revision for publication on 2 October 2006.

DOI: $10.1243 / 1464419 J M B D 41$

\begin{abstract}
This article presents transient handling analysis with a full-vehicle non-linear multi-body dynamic model, having 102 degrees of freedom. A transient cornering manoeuvre, with a constant steer angle and velocity has been undertaken. The effects of aerodynamic lift and drag forces have been included in the simulation tests. The vehicle handling characteristics with and without aerodynamic forces have been compared and various observations made. The aerodynamic forces have been predicted by a $k-\varepsilon$ model solution of the Navier-Stokes equations for turbulent flow. The numerical predictions for the evaluation of aerodynamic lift coefficient agrees well with the scaled-down air tunnel experimental work, using hot-wire anemometry.
\end{abstract}

Keywords: multi-body dynamics, aerodynamics, handling, non-linear characteristics, suspension, steering, tyre, stability

\section{INTRODUCTION}

Multi-body dynamic models, incorporating vehicle suspension and steering geometry, chassis and vehicle body have been employed to study ride comfort and vehicle handling characteristics for the past four to five decades. The advantage of this approach is in rapid scenario-building simulation studies and a corresponding reduction in the vehicle development cycle time. The initial analysis techniques have dealt with linear dynamic analysis, particularly for steadystate motions $[\mathbf{1}]$. The problem with these simplified models has been the restriction in simulation output accuracy to lateral accelerations up to $0.3 \mathrm{~g}$. With the advent of independent suspensions the vehicle technology has moved on, with most modern saloon type vehicles being capable of cornering manoeuvres of up to $0.8 \mathrm{~g}$. Furthermore, there are many sources of non-linearity in suspension kinematics, steering characteristics, tyre deformation properties, and inertial dynamics in roll, pitch, and yaw motions.

\footnotetext{
${ }^{*}$ Corresponding author: School of Engineering, Design and Technology, University of Bradford, Richmond Road, Chesham building, Bradford BD7 IDP, UK. email: k.hussain1@ bradford.ac.uk
}

These have necessitated the development of more complex non-linear dynamic models [2-5].

To ensure rigorous testing of vehicle stability, some severe steered conditions have been reported, for example a $210^{\circ}$ steering ramp within $0.4 \mathrm{~s}$ while using a 42 degrees of freedom non-linear multibody model [2]. The exact nature of a manoeuvre has been debated for a long time, culminating in a number of standardized tests embodied in, for example the British Standard or in ISO for the given types of motion such as lane change, slalom, and in cornering [6]. Nevertheless, carrying out a realistic simulation study necessitates the use of proven tyre models. Much research has been devoted to this crucial area of simulation studies, culminating in the creation of tyre models that can be employed for given simulation conditions [7].

Another important factor necessary for realistic vehicle handling analysis is the inclusion of aerodynamic forces in the simulation study. The presence of aerodynamic forces in vehicle handling simulations leads to predictions that can realistically be compared with vehicle test data. Hitherto, combined numerical solutions for handling manoeuvres with aerodynamic forces have rarely been reported, particularly under transient conditions for small to medium cars. Much more attention has been paid 
to aerodynamic interactions with a static vehicle, particularly for long and tall vehicles, such as for trucks and trains [8]. Much of the aerodynamic studies have clearly focused on the measurement or prediction of aerodynamic forces, mostly with a slant on the reduction of drag forces for given vehicle shapes $[\mathbf{8}, 9]$. Most studies utilize a vehicle in rest position, either in an air tunnel or for numerical predictions. Fair or good agreement has now been obtained for most such studies between the numerical simulations and either full-scale or scaled-down vehicle air tunnel tests [10]. Some basic vehicle dynamic analysis with side gust has been reported by various authors [11]. However, the study of interactions between vehicle dynamics and aerodynamic forces has not received the same level of attention. This article presents an approach for the interaction between vehicle inertial dynamics and aerodynamic forces under transient manoeuvres.

There is now a good body of literature for the numerical prediction of airflow field over a vehicle. Solutions are required to Navier-Stokes equations, representing conservation of mass, momentum, and energy. A number of methods have been employed for this purpose; finite difference, finite volume, and finite element analysis. The realistic flow representation around a ground vehicle requires the inclusion of a complex field within the viscous region of the boundary layer, and the swirling vortices in the wake which extend to the far field of the freestream. Numerical solutions for such mixed flow conditions with large eddies and full transient time-dependency are not feasible at present. However, the effect of turbulence should be accounted for in the time-averaged Navier-Stokes equations. This has been achieved using $k-\varepsilon$ models to represent the intensity and length scale of turbulent flow [12]. This article employs such a model to predict the flow field around a vehicle and validate its findings against the results obtained from hot-wire anemometry in a scaled-down vehicle model. The numerical results are then employed to calculate the drag and lift coefficients to be employed in a full-vehicle non-linear multi-body dynamic model during a transient cornering manoeuvre.

\section{THE VEHICLE MULTI-BODY DYNAMIC MODEL}

A full non-linear vehicle dynamic model was constructed for this research, using the automatic dynamic analysis of mechanical system software. The model comprises a vehicle body, a front and rear double wishbone suspensions, a rack and pinion steering system, an anti-roll bar, and the wheel assembly. The centre of gravity of the vehicle is situated at: 1141, 0, 538 in the global frame of reference at the rest position.

Vehicle motions are described in terms of the fixed global frame of reference $X, Y, Z$, as shown in Fig. 1 . Local part frames of reference $x_{i}, y_{i}, z_{i}$ are attached to all the moving parts $i$. A generic formulation method, based on the Lagrange's equation for constrained systems is employed for the derivation of equations of motion for all parts in the model in body 3-1-3 Euler frame of reference.

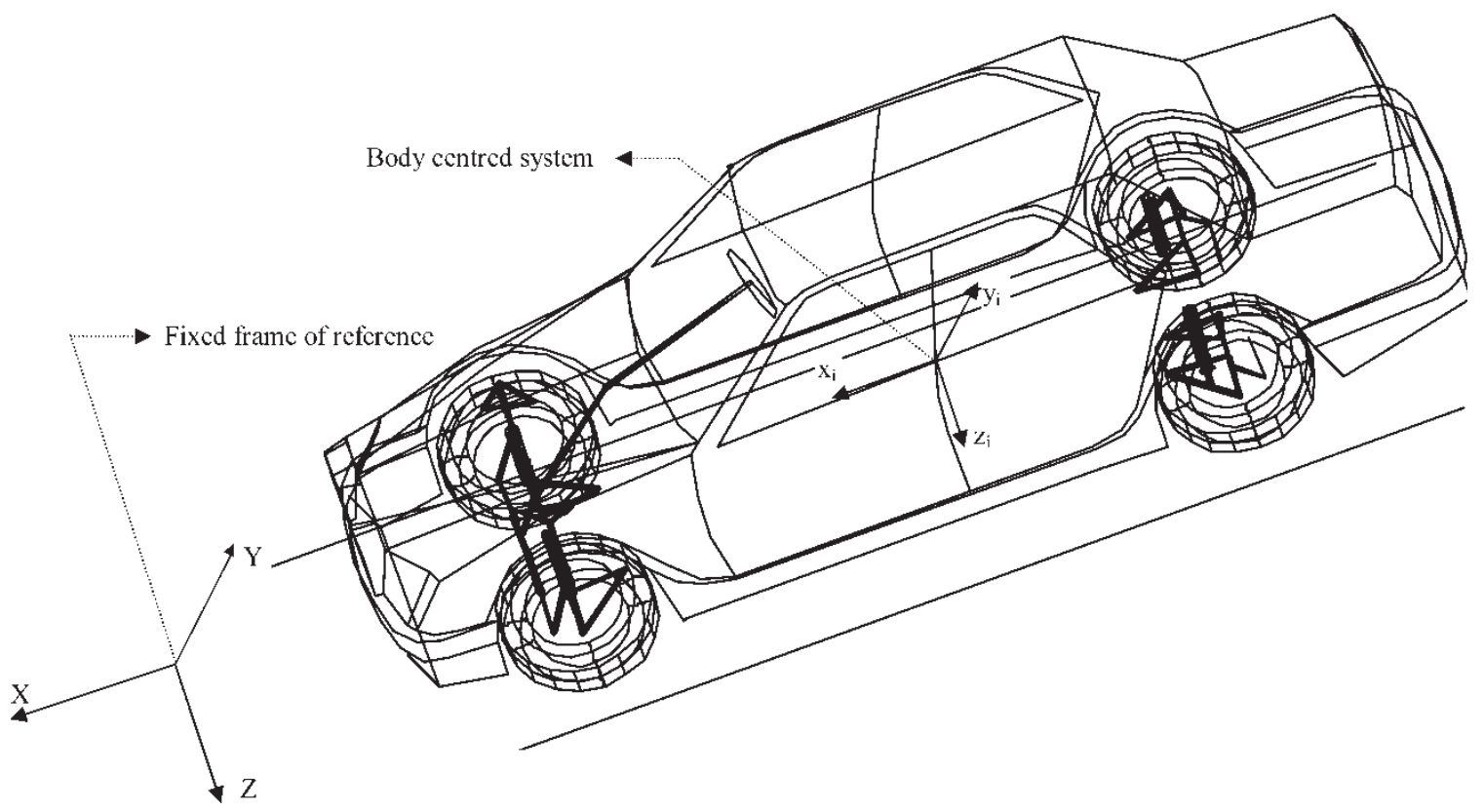

Fig. 1 The axis system for the vehicle model 


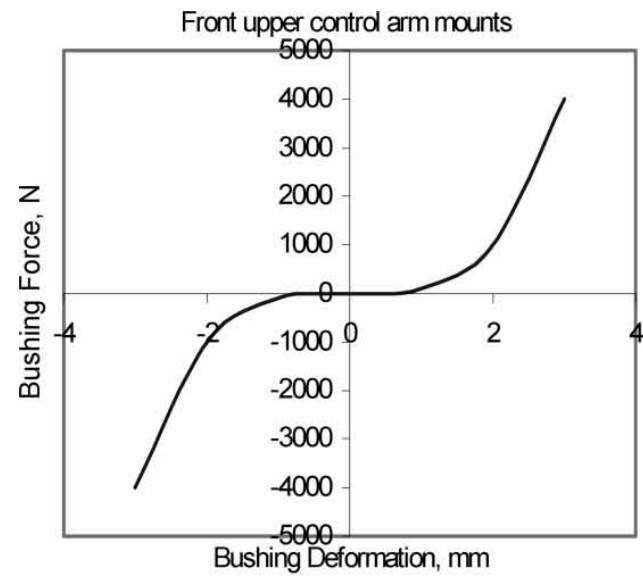

2(a): Sub-frame mounts

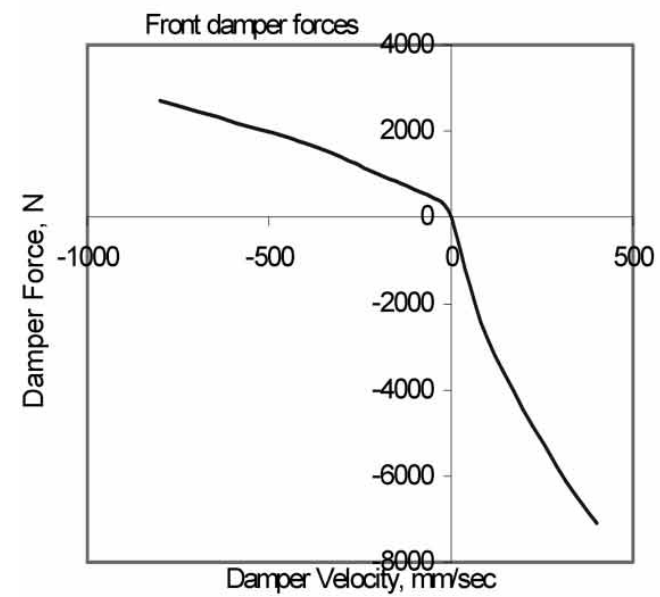

2(c): Front damper characteristics

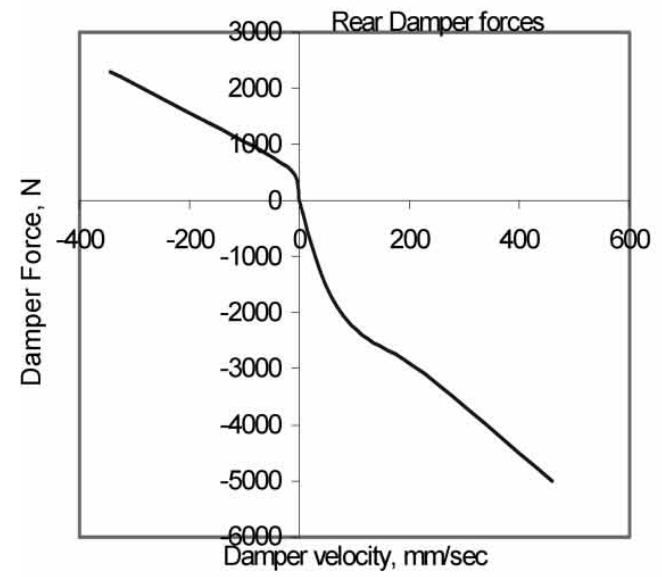

2(d): Rear damper characteristics

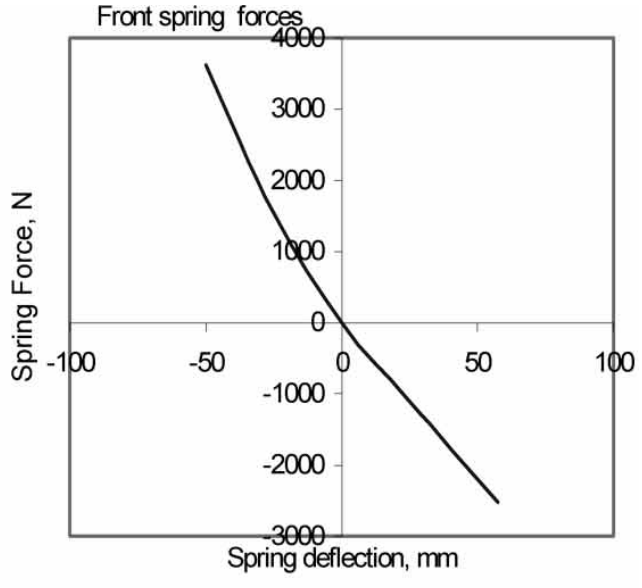

2(b): Front spring characteristics

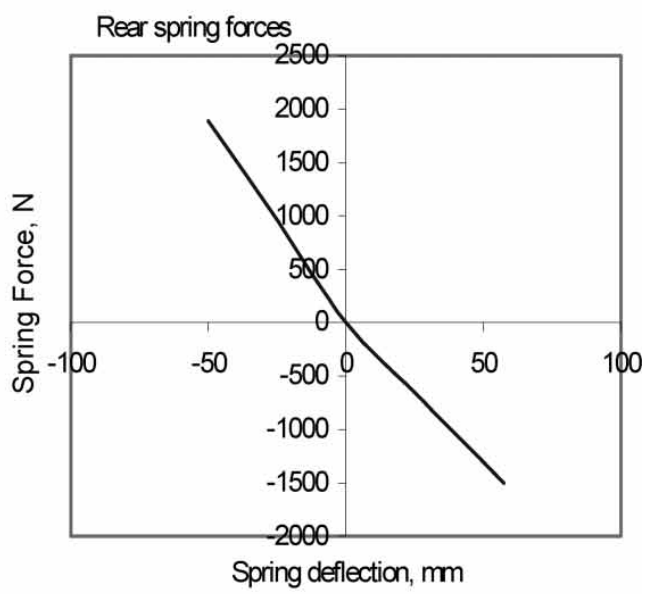

2(d): Rear spring characteristics

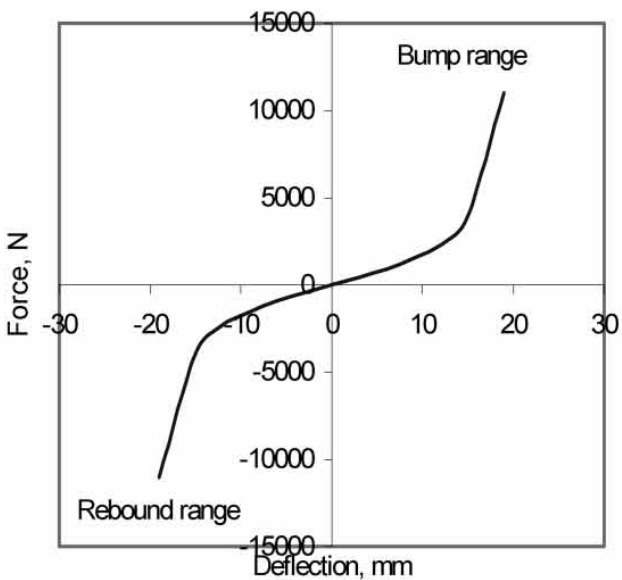

2(f): Bump and Rebound stop force characteristics

Fig. 2 Sources of compliance in the vehicle model

Figure 2 shows the variation of non-linear compliant elements in the suspension system. A full description of these, the suspension and steering geometry are provided in reference [6].
The Grüebler-Kützbach expression can be used to determine the available degrees of freedom in the vehicle model. There are 38 parts in the vehicle model, excluding ground (Table 1). The number of 
Table 1 Mass and inertial properties in the vehicle model

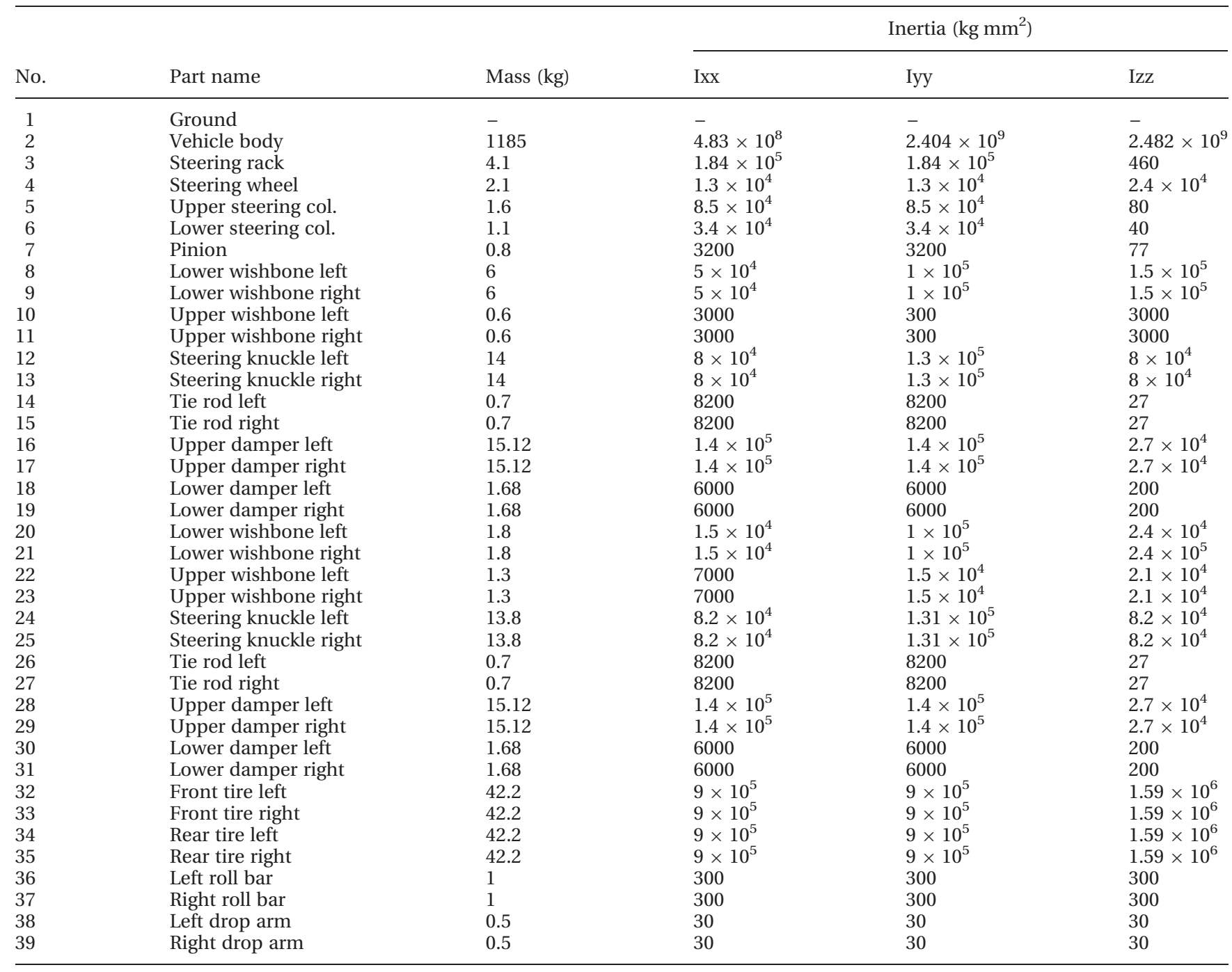

constraints for each joint, coupler, and specified motions is given in Table 2. Thus

$$
\begin{aligned}
n_{\text {DOF }} & =6 n-\sum \text { Constraints }=6 n-m \\
& =6(38)-126=102
\end{aligned}
$$

\subsection{Tyre modelling}

The tyre model is a combination of the magic formula, developed by Bakker et al. [13], and the Fiala tyre model [14]. This formulation is used to calculate the longitudinal tyre force, $F_{x}$, the lateral type force $F_{y}$, and the self-aligning moment $M_{z}$ as functions of the vertical force $F_{z}$, the slip ratio $S$, the side slip angle $\alpha$, and the camber angle $\gamma$.

The radial tyre contact force acts in the radial plane of the tyre. Its component, acting in the direction of the contact normal at the tyre-road contact patch, is used to calculate the tyre vertical force. The radial force is dependent on the tyre deflection and its rate of change, both measured along the tyre vertical directional vector. The tyre-damping ratio can be neglected since the product of the velocities in the tyre contact patch and the damping ratio in the tyre was quite low; hence, the vertical force can be computed using equation (2). However, it is advisable for most applications to include the damping contribution to the vertical force

$$
F_{z}=C_{z} \delta
$$

The longitudinal tyre force is dependent on the longitudinal slip ratio and the longitudinal stiffness [14] and is computed as follows

$$
\begin{aligned}
& S=\frac{V_{\mathrm{c}}}{u} \\
& S^{*}=\frac{\mu F_{z}}{2 C_{\mathrm{s}}}
\end{aligned}
$$


Table 2 Assembly constraints in the vehicle model

\begin{tabular}{|c|c|c|c|c|}
\hline No. & Constraint type & Part I & Part J & $\begin{array}{l}\text { No. of } \\
\text { constraints }\end{array}$ \\
\hline 1 & Revolute joint / 26 & Steering wheel & Upper steering col. & 5 \\
\hline 2 & Revolute joint /33 & Upper steering col. & Vehicle body & 5 \\
\hline 3 & Universal joint & Upper steering col. & Lower steering col. & 4 \\
\hline 4 & Universal joint & Lower steering col. & Pinion & 4 \\
\hline 5 & Cylindrical joint /54 & Pinion & Vehicle body & 4 \\
\hline 6 & Transnational joint /61 & Steering rack & Vehicle body & 5 \\
\hline 7 & Spherical joint & Lower wishbone left & Steering knuckle left & 3 \\
\hline 8 & Spherical joint & Lower wishbone right & Steering knuckle right & 3 \\
\hline 9 & Spherical joint & Upper wishbone left & Steering knuckle left & 3 \\
\hline 10 & Spherical joint & Upper wishbone right & Steering knuckle right & 3 \\
\hline 11 & Spherical joint & Steering knuckle left & Tie rod left & 3 \\
\hline 12 & Spherical joint & Steering knuckle right & Tie rod right & 3 \\
\hline 13 & Universal joint & Steering rack & Tie rod left & 4 \\
\hline 14 & Universal joint & Steering rack & Tie rod right & 4 \\
\hline 15 & Cylindrical joint & Upper damper left & Lower damper left & 4 \\
\hline 16 & Cylindrical joint & Upper damper right & Lower damper right & 4 \\
\hline 17 & Spherical joint & Lower wishbone left & Steering knuckle left & 3 \\
\hline 18 & Spherical joint & Lower wishbone right & Steering knuckle right & 3 \\
\hline 19 & Spherical joint & Upper wishbone left & Steering knuckle left & 3 \\
\hline 20 & Spherical joint & Lower wishbone right & Steering knuckle right & 3 \\
\hline 21 & Spherical joint & Steering knuckle left & Tie rod left & 3 \\
\hline 22 & Spherical joint & Steering knuckle right & Tie rod right & 3 \\
\hline 23 & Cylindrical joint & Upper damper left & Lower damper left & 4 \\
\hline 24 & Cylindrical joint & Upper damper. right & Lower damper right & 4 \\
\hline 25 & Revolute joint & Steering knuckle left & Front tire left & 5 \\
\hline 26 & Revolute joint & Steering knuckle right & Front tire right & 5 \\
\hline 27 & Revolute joint & Steering knuckle left & Rear tire left & 5 \\
\hline 28 & Revolute joint & Steering knuckle right & Rear tire right & 5 \\
\hline 29 & Revolute joint & Vehicle body & Left roll bar & 5 \\
\hline 30 & Revolute joint & Vehicle body & Right roll bar & 5 \\
\hline 31 & Spherical joint & Left roll bar & Left drop arm & 3 \\
\hline 32 & Spherical joint & Right roll bar & Right drop arm & 3 \\
\hline 33 & Coupler & Joint 54 & Joint 61 & 1 \\
\hline 34 & Motion & \multicolumn{2}{|c|}{ Joint 26} & 1 \\
\hline 35 & Motion & \multicolumn{2}{|c|}{ Joint 33} & 1 \\
\hline \multicolumn{4}{|c|}{$\sum C_{k}$} & 126 \\
\hline
\end{tabular}

where

$$
\begin{aligned}
C_{\mathrm{s}} & =\left.\frac{\partial F_{x}}{\partial S}\right|_{S=0} \\
F_{x} & = \begin{cases}-C_{\mathrm{s}} S & |S| \leqslant\left|S^{*}\right| \\
-\left(F_{x 1}-F_{x 2}\right)^{*} \operatorname{Sign}(1, S) & |S|>\left|S^{*}\right|\end{cases}
\end{aligned}
$$

where

$$
\begin{aligned}
& F_{x 1}=\mu *\left|F_{z}\right| \\
& F_{x 2}=\frac{\left(\mu * F_{z}\right)^{2}}{\left(4 *|S| * C_{\mathrm{s}}\right)}
\end{aligned}
$$

The lateral force and self-aligning moment are expressed as a function of the slip angle [7]

$$
\begin{aligned}
& F_{y}=D \sin (C \arctan (B \phi))+S_{\nu} \\
& \phi=(1-E)\left(\alpha+S_{h}\right)+\left(\frac{E}{B}\right) \arctan \left(B\left(\alpha+S_{h}\right)\right)
\end{aligned}
$$

where $B, C, D, E, S_{\mathrm{v}}$, and $S_{h}$ are six coefficients, which depend on $F_{z}$ and on the camber angle, $\gamma$. They must be obtained by experimental testing [15] and do not have any direct physical meaning. In particular, $S_{v}$ and $S_{h}$ have been introduced for ply steer and conicity for $F_{y}$ and $M_{z}$ when $\alpha=0$.

The rolling resistance is negative when the tyre is rolling forward and positive when the tyre is rolling backward. It is computed as

$$
M_{y}=\mp C_{\mathrm{r}} F_{z}
$$

\subsection{Vehicle inertial dynamics}

There are 38 parts in the multi-body model as listed in Table 1, the motion of each of which can be described in terms of the generalized coordinates, $q$ using the Lagrange's equation for constrained systems as

$$
\frac{\mathrm{d}}{\mathrm{d} t}\left(\frac{\partial K}{\partial \dot{q}}\right)-\frac{\partial K}{\partial q}-F_{q}+\sum_{k=1}^{m} \lambda_{k} \frac{\partial C_{k}}{\partial q}=0
$$

The generalized coordinates are given by: $\{q\}^{\mathrm{T}}=\{x y z \psi \theta \theta \phi$, where the rotational components 
are the Euler angles in body 3-1-3 successive rotations.

The joint reactions are given by the summation term in equation (12), along each of the generalized coordinates. These are introduced by the holonomic constraint functions, $C_{k}$. Therefore, the assembly of parts can be represented mathematically in a manner that conforms to the required dynamic functions of the system.

The set of differential equations of motion is solved simultaneously with the holonomic algebraic constraint functions, the applied forces, and compliance functions (e.g. tyre forces, bushing reactions) in small discrete steps of time. The vector of unknowns includes the system state variables such as position, velocity, and acceleration of all parts, and the Lagrange multipliers, representing the joint reactions. Thus, in the matrix form the set of equations are represented by [2]

$$
[\mathrm{J}]\{q, \lambda\}^{\mathrm{T}}=\left\{F_{q}\right\}
$$

The Jacobian matrix is of the following form

$$
[\mathbf{J}]=\left[\begin{array}{cc}
{\left[\frac{\mathrm{d}}{\mathrm{d} t} \frac{\partial K}{\partial \dot{q}}+\frac{\partial K}{\partial q}\right]} & {\left[\frac{\partial C}{\partial \lambda}\right]} \\
{\left[\frac{\partial C}{\partial q}\right]} & {[0]}
\end{array}\right]
$$

Ideal functions in all mechanisms are assured by the appropriate use of constraints in the form of joints or attachments. Each joint or an assembly attachment introduces constraint functions in the form of non-linear algebraic equations. Table 2 lists the different types of joints employed in the assembly of various parts in the vehicle model. Typical constraint functions for multi-body vehicle models are provided in references [6] and [16]. When the motion of a part is allowed but subjected to a compliance function as in bushings, the forcing element is referred to as a restraint.

There are, in fact, 126 constraint functions in the present full-vehicle model.

Now referring back to equation (14), the constraint function $C$ is used to set up the matrices $(C /) \lambda$, being the Lagrange multiplier coefficient, and $(\mathrm{C} / \mathrm{)} \mathrm{q}$, being the constraint-related function.

The top left-hand terms in the Jacobian matrix give the inertial submatrix for the various degrees of freedom in the vehicle model. The applied forces: tyre forces and suspension bushing, spring, shock absorber, jounce, and rebound bumper reactions are given in $\left\{F_{q}\right\}$.

There are six equations of motion for each part in the model, represented in terms of firstorder derivatives, using the substitution: $\{\varphi\}=\{\dot{q}\}$.
This substitution is applied for translational degrees of freedom; $x, y, z$. For rotational degrees of freedom, the equations of motion are given in terms of the rate of change of momenta; $\dot{M}_{\psi}, \dot{M}_{\theta}, \dot{M}_{\phi}$, where

$$
\left\{M_{\psi}, M_{\theta}, M_{\phi}\right\}^{\mathrm{T}}=\left\{\frac{\partial K}{\partial \dot{\psi}}, \frac{\partial K}{\partial \dot{\theta}}, \frac{\partial K}{\partial \dot{\phi}}\right\}^{\mathrm{T}}
$$

Thus, for the rotational degrees of freedom the three equations of momenta in equation (15) should be included in the analysis. Therefore, there are 15 differential equations for each part within the multi-body model, making a total of 550 differential equations for the 38 parts in the model. To this are added 126 algebraic constraint functions, introduced by the constraints listed in Table 2. There are also forces due to restraining elements such as shock absorber, bushings, bump and rebound stops, and the roll resistive torque of the anti-roll bar. In addition to these, there are the tyre forces described above for all the four road wheels. The applied forces include the tyre forces and the aerodynamic lift and drag (described in section 4).

The solution method involves lower-upper (LU) factorization of the Jacobian matrix in each step of time for this differential-algebraic set of equations, using the Newton-Raphson method with a stepby-step integration of state variable derivatives using a Gear type integration algorithm [17]. The procedure is detailed in reference [18].

\section{THE SCALED VEHICLE WIND TUNNEL TEST}

The transient aerodynamic resistance of the vehicle is initially investigated using a 1:10th scale model of the actual vehicle. The Reynolds' number for wind tunnel and full-scale vehicle should ideally be in the same order of magnitude. If geometrically a scale model has the same Reynolds' number as the actual vehicle itself, then the flow patterns would usually be identical. This is not always possible due to limitations with tunnel specifications. However, similar airflow can be ensured with minimum Reynolds' number flow in the air tunnel. Values for wind tunnel practice have been set by SAE, for example see the recommended practice J1252 $[19,20]$. In any case, the drag coefficient becomes almost constant for Reynolds' numbers in excess of $0.25 \times 10^{6}[\mathbf{2 1}]$. The wind tunnel tests carried out in this article are based on Reynolds' number for the vehicle length as $0.7 \times 10^{6}$, which is within the recommended values set by the SAE [21]. It is advisable to study the airflow with a scaled model, backed up 
by numerical prediction, having the same Reynolds' number. This approach has been adopted in this article. While an agreement has been obtained, the numerical method can be employed to obtain the lift and drag coefficients to be used in the vehicle inertial dynamic simulations.

The test section of the wind tunnel used is square, $600 \times 600 \mathrm{~mm}$ in cross-section. The maximum velocity in the test section is approximately $20 \mathrm{~m} / \mathrm{s}$.

The vehicle is aligned longitudinally (i.e. with zero yaw) inside the wind tunnel. The velocity components over the vehicle body have been measured, using two-dimensional hot-wire anemometry. The results obtained for the drag and lift coefficients can then be used in the vehicle dynamic analysis for simulation studies that do not pertain to the incidence of significant side gusts. Furthermore, it has been shown in practice that neglecting the effect of vehicle roll in theoretical treatment is quite justified [22]. The pressure distribution over the vehicle body was approximated using the Bernoulli's equation for laminarfree stream as

$$
C_{\mathrm{P}}=\frac{P_{2}-P_{1}}{(1 / 2) \rho U_{1}^{2}}=\frac{U_{1}^{2}-U_{2}^{2}}{U_{1}^{2}}+\frac{2 g\left(Z_{1}-Z_{2}\right)}{U_{1}^{2}}
$$

The drag exerted on an immersed body by a moving fluid arises from two mechanisms only. The first is due to the viscous surface shear stress, and is referred to as skin friction. The second is due to the pressure distribution around the body, and is called the form drag. The total drag force is most conveniently expressed in terms of the non-dimensional drag coefficient as

$$
C_{\mathrm{D}}=\frac{F_{\mathrm{D}}}{(1 / 2) \rho u^{2} A_{\mathrm{f}}}
$$

The lift force is due to the difference in the various pressure zones on the opposite sides of the vehicle's over and under body. It is always perpendicular to the direction of the incoming airflow. The total lift force is most conveniently expressed in terms of the non-dimensional lift coefficient as

$$
C_{\mathrm{L}}=\frac{F_{\mathrm{L}}}{(1 / 2) \rho u^{2} A_{\mathrm{p}}}
$$

\section{THE COMPUTATIONAL AERODYNAMIC ANALYSIS}

The simulation of flows over and under the vehicle body in a wind tunnel was carried out using the computer code CFX-4 [23]. This includes two main steps: one is creating the geometry file for the scaled model; the second is creating a command file for the fluid flow properties such as the type of flow (laminar or turbulent), the inlet free stream velocity, fluid density and viscosity. The CFX-4 software employs a second-order accuracy finite volume solver [23]. On an average, 40000 regular mesh elements were used in the simulation study. Although, a larger mesh would normally be desired, sensitivity analysis has shown that a computational mesh of the 40000 mesh points satisfies for the site of the model described. Typically, 500 iterations were needed on a Sunsparc 20 Workstation, with a CPU time of $6216 \mathrm{~s}$ to obtain the results.

The fundamental equations of fluid dynamics are based on the universal laws of conservation of mass, momentum, and energy. These are described by the Navier-Stokes equations. The effect of turbulence is accounted for in the time-averaged Navier-Stokes equations by the inclusion of a $k-\varepsilon$ model as

For mass conservation

$$
\frac{\partial \bar{U}}{\partial x}+\frac{\partial \bar{V}}{\partial y}+\frac{\partial \bar{W}}{\partial z}=0
$$

For conservation of momentum

$$
\begin{aligned}
& \rho\left(\bar{U} \frac{\partial \bar{U}}{\partial x}+\bar{V} \frac{\partial \bar{U}}{\partial y}+\bar{W} \frac{\partial \bar{U}}{\partial z}\right) \\
& =-\frac{\partial \bar{P}}{\partial x}+\mu \nabla^{2} \bar{U}-\rho\left[\frac{\partial \overline{u^{2}}}{\partial x}+\frac{\partial \overline{u v}}{\partial y}+\frac{\partial \overline{u w}}{\partial z}\right] \\
& \rho\left(\bar{U} \frac{\partial \bar{V}}{\partial x}+\bar{V} \frac{\partial \bar{V}}{\partial y}+\bar{W} \frac{\partial \bar{V}}{\partial z}\right) \\
& =-\frac{\partial \bar{P}}{\partial y}+\mu \nabla^{2} \bar{V}-\rho\left[\frac{\partial \overline{u v}}{\partial x}+\frac{\partial \overline{v^{2}}}{\partial y}+\frac{\partial \overline{v w}}{\partial z}\right] \\
& \rho\left(\bar{U} \frac{\partial \bar{W}}{\partial x}+\bar{V} \frac{\partial \bar{W}}{\partial y}+\bar{W} \frac{\partial \bar{W}}{\partial z}\right) \\
& \quad=-\frac{\partial \bar{P}}{\partial z}+\mu \nabla^{2} \bar{W}-\rho\left[\frac{\partial \overline{u w}}{\partial x}+\frac{\partial \overline{v w}}{\partial y}+\frac{\partial \overline{w^{2}}}{\partial z}\right]
\end{aligned}
$$

where

$$
\nabla^{2}=\frac{\partial^{2}}{\partial x^{2}}+\frac{\partial^{2}}{\partial y^{2}}+\frac{\partial^{2}}{\partial z^{2}}
$$


The governing equations for the turbulent kinetic energy and dissipation rate are

$$
\begin{aligned}
& \rho U_{j} \frac{\partial K}{\partial x_{j}}=\frac{\partial}{\partial x_{i}}\left(\frac{\mu_{\mathrm{t}}}{\sigma_{k}} \frac{\partial K}{\partial x_{j}}\right)-\rho \overline{u_{i} u_{j}} \frac{\partial U_{i}}{\partial x_{j}}-\rho \varepsilon \\
& \rho U_{j} \frac{\partial \varepsilon}{\partial x_{j}}=\frac{\partial}{\partial x_{i}}\left(\frac{\mu_{t}}{\sigma_{\varepsilon}} \frac{\partial \varepsilon}{\partial x_{j}}\right)-C_{1} \frac{\varepsilon}{k} \rho \overline{u_{i} u_{j}} \frac{\partial U_{i}}{\partial x_{j}}-C_{2} \rho \frac{\varepsilon^{2}}{K}
\end{aligned}
$$

where

$$
\rho \overline{u_{i} u_{j}}=\frac{2}{3} \rho \delta_{i j} K-\mu_{\mathrm{t}}\left(\frac{\partial U_{i}}{\partial x_{j}}+\frac{\partial U_{j}}{\partial x_{i}}\right)
$$

where $\mu_{\mathrm{t}}$ is the turbulent viscosity coefficient and $\delta_{i j}$ is the Kronecker delta, with $\delta_{i j}=1$ when $i=j$ and $\delta_{i j}=0$ if $i \neq j$.

\section{RESULTS AND DISCUSSION}

Figure 3 illustrates an animated output for the transient cornering manoeuvre during a simulation time of $5 \mathrm{~s}$. Two thousand steps of simulation were undertaken after an initial static equilibrium analysis on a flat road. A number of simulation studies were performed with and without aerodynamic forces.

The drag and lift coefficients were obtained numerically using the method highlighted in section 4. The numerical method employed was initially validated against experimental wind-tunnel test for a 1:10th scaled vehicle model. Figure 4 shows the experimentally obtained pressure coefficient, $C_{\mathrm{P}}$, and the corresponding values through numerical prediction along the centre-line of the vehicle in this instance. The numerical predictions overall agree well with the experimental results, with some differences at the rear of the vehicle. Clearly, the vortex flow at the rear of the vehicle cannot be predicted correctly by the numerical method used. The shape of the variations in $C_{\mathrm{P}}$, obtained experimentally agrees well with the wind-tunnel tests reported by other authors [24]. There are some differences at the front of the vehicle (on the bonnet) between the numerical trends and the experimental variations. This is because in the numerical work a flat panel was used to represent the usual shape which is in fact more complex (Fig. 1). As a result, the usual over-pressure characteristics are absent. Nevertheless, the numerical predictions are quite satisfactory as shown in the prediction of $C_{\mathrm{P}}$ for the underbody in Fig. 4. This indicates corresponding rising values in the wheel arch locations, as also observed experimentally, for example by Cogotti [24].

By analysing the pressures in the longitudinal and vertical directions in Fig. 4, the drag and lift coefficients are obtained as

$$
\begin{aligned}
& C_{\mathrm{D}}=0.421 \\
& C_{\mathrm{L}}=0.548
\end{aligned}
$$

By applying the drag and lift coefficients, the projected and the lift area in equations (17) and (18), the aerodynamic drag and lift forces are expressed as a function of speed as follows

$$
\begin{aligned}
& D=\frac{1}{2}(1.2)(0.421)(3.18) U^{2}=0.70786 U^{2} \\
& L=\frac{1}{2}(1.2)(0.548)(9.6594) U^{2}=3.176 U^{2}
\end{aligned}
$$

These forces were incorporated into the vehicle model described in section 3 . They were represented as overall lift and drag forces, applied at the centre of gravity of the vehicle. Putting these forces at the centre of gravity neglects possible moment loading.

A measure of the vehicle stability is the roll of the vehicle due to lateral weight transfer while cornering. The vehicle model includes an anti-roll bar, in order to obtain realistic roll characteristics for the vehicle during the cornering manoeuvre. The cornering manoeuvre is undertaken at $110 \mathrm{~km} / \mathrm{h}$, which is the maximum motorway speed in the UK.

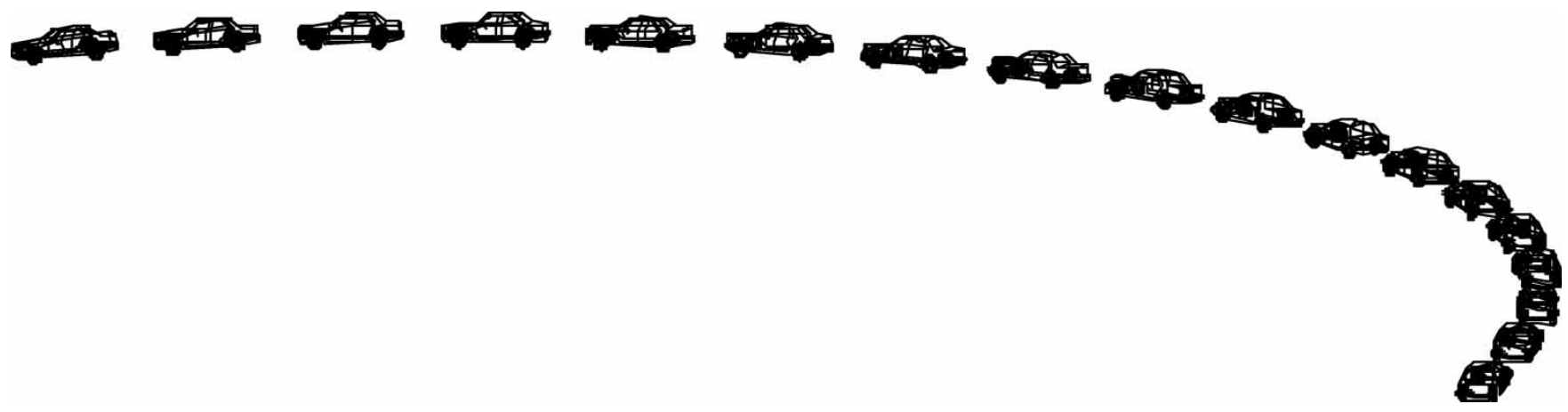

Fig. 3 Vehicle cornering manoeuvre for $5 \mathrm{~s}$ of simulations 

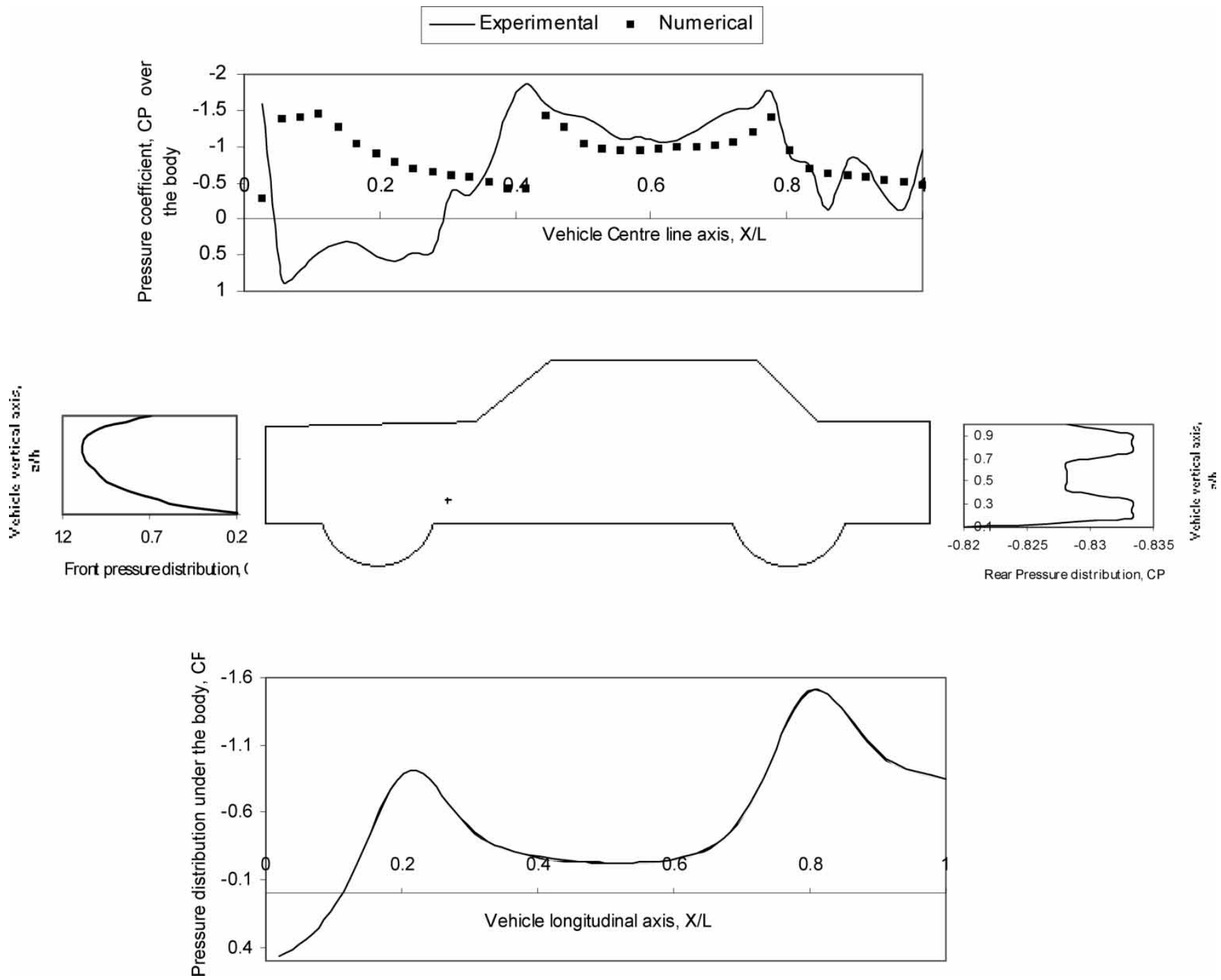

Fig. 4 Experimental and numerical pressure coefficient distribution

With most modern vehicles' lateral accelerations, upto $0.8 \mathrm{~g}$ with typical body rolls in the region $2-8^{\circ}$ is attainable. Figure 5 shows the vehicle roll angle variations while negotiating the corner with and

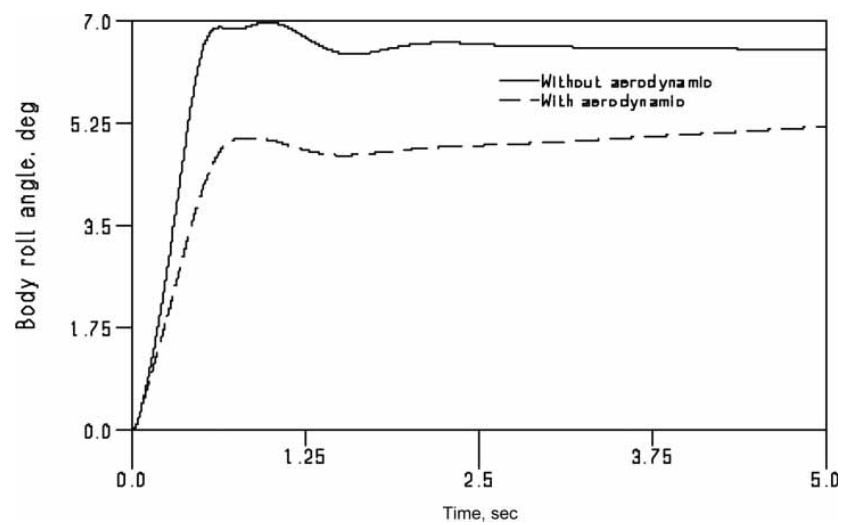

Fig. 5 Vehicle body roll angle during the cornering manoeuvre without the inclusion of the aerodynamic forces. In both cases, the body roll increases prior to reaching the corner and levels off when the corner is negotiated. It can be noted that without the aerodynamic

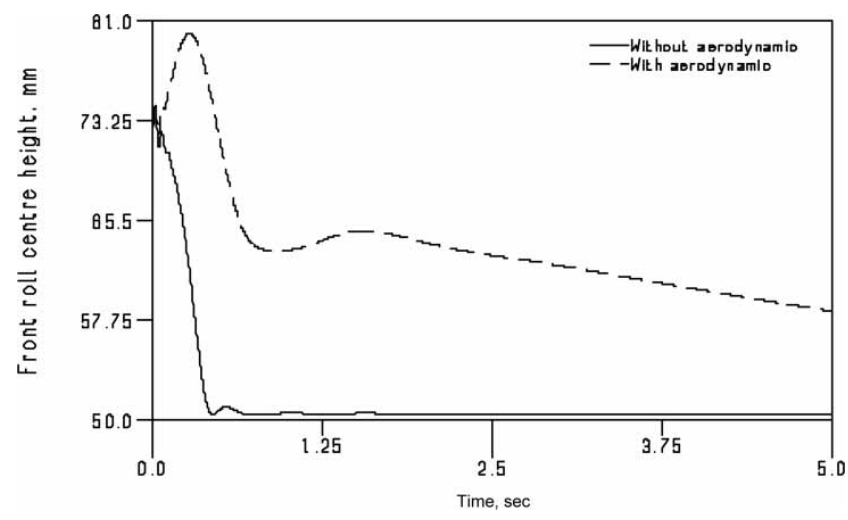

Fig. 6 Instantaneous front roll centre height 


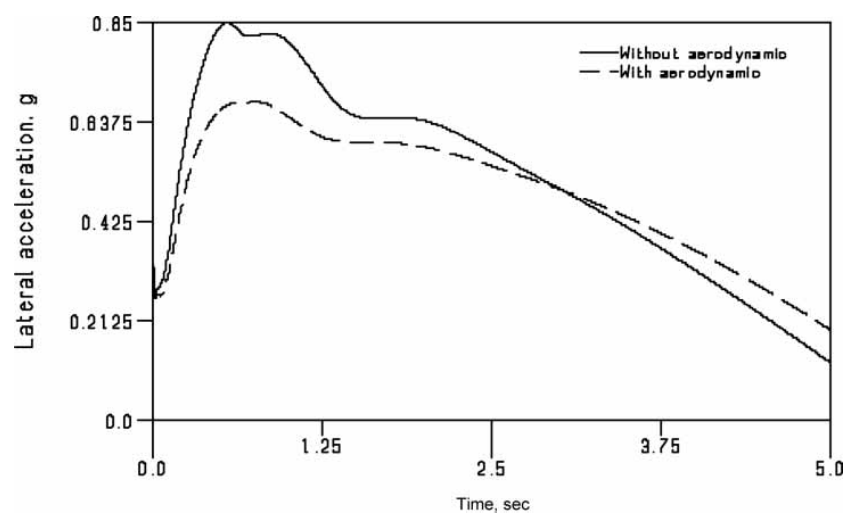

Fig. 7 Lateral acceleration during the cornering manoeuvre

forces the weight transfer from the inside to the outside is more significant, thus resulting in a greater maximum roll angle during the manoeuvre. This is expected as the aerodynamic lift reduces the lateral weight transfer. A lower roll angle translates to enhanced vehicle stability. This fact is further demonstrated by a less severe change in the front or the rear roll centre heights (see Fig. 6 for the variation in the front roll centre height). With a greater variation in the roll centre height away from the centre of gravity of the vehicle, a greater moment and a larger centrifugal force is expected. Therefore, the vehicle is subjected to a higher lateral acceleration without the aerodynamic effect (Fig. 7). An approximate 20 per cent reduction in lateral acceleration is observed when negotiating the bend, which is quite significant, fairly moderate at this speed. This indicates that the aerodynamic effect without side gust is likely to ease the cornering effort and is in-line with common wisdom. It would also indicate better passenger comfort because of reduced centrifugal effect. The observations thus far point to the beneficial effect of aerodynamic forces, particularly if cornering speeds were to be increased. However, vehicle stability can also be affected by vehicle adherence to the road (i.e. sufficient tyre forces).

With aerodynamic effect, the increased lift renders lower tyre forces, as can be observed in Fig. 8. Due to the lateral weight transfer, there is an increase in the vertical tyre forces on the outside and a corresponding decrease in the vertical tyre forces on the inside wheels. A measure of vehicle stability is the loss of contact, indicated by the inside wheels' tyre forces. With the aerodynamic lift, there is an additional problem in the diminution of tyre forces on all wheels. The loss of vertical tyre force on the outside (while still having a sufficient value) can lead to a reduction in tyre wear, which has a beneficial effect. However, the likely reduction in tyre forces

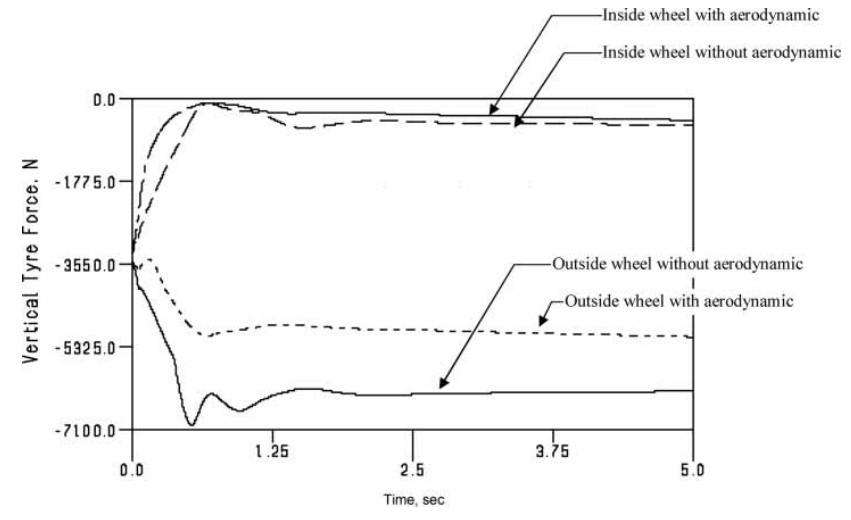

Fig. 8 Vertical tyre forces during the cornering manoeuvre

on the inside wheels would result in loss of contact and lead to vehicle instability. However, it can be observed that the vertical tyre force on the inside wheel remains almost unchanged with aerodynamic effect (Fig. 8).

It is worth noting that the approach to include the aerodynamics forces within the multi-body vehicle handling simulation in this work has been followed in a serial fashion by calculating the aerodynamics forces first. These were then input to the vehicle simulation model. Hence, the changes to the aerodynamic forces due to changes in the vehicle's attitude during cornering were not included in this study. The modelling can be enhanced if a simultaneous and parallel analysis can be implemented in which instantaneous interactions are accounted for within a unified simulation environment. Currently by available computer power still restricts such a large analysis to be carried out.

\section{CONCLUSIONS}

This article has highlighted some of the important aspects that have to be taken into account for realistic vehicle handling analysis. The vehicle model developed in this research can also be used to recover detailed information such as the loading in the suspension joints, bump stops, and other vehicle transient behaviour. Such analysis may include durability studies or traction for off road vehicle with appropriate terramechanics included. For the pure vehicle handling analysis simpler models with sufficient detail may well suffice. The significance of appropriate tyre models have been outlined, as well as the inclusion of aerodynamic effects; lift and drag forces. It has been shown that aerodynamic forces can contribute significantly to the cornering performance of vehicles. Transient dynamic analysis in vehicle handling is set to dominate the simulation 
studies in the future. The inclusion of aerodynamic interactions during such manoeuvres must be assured. Further investigations should encompass the effect of side gusts and the determination of lift and drag coefficients in wind tunnel tests with finite values of vehicle yaw.

\section{ACKNOWLEDGEMENT}

The authors wish to express their gratitude to the Egyptian Military Attache's Office for the financial support extended to this research project.

\section{REFERENCES}

1 Segel, L. Theoretical prediction and experimental substantiation of the response of the automobile to steering control in research in automobile stability and control and in tyre performance. Proc. Instn Mech. Engrs (A.D.), 1959-57, 7, 310-330.

2 Orlandea, N. and Chace, M. A. Simulation of a vehicle suspension with ADAMS computer program. SAE technical paper, no. 770053, 1977, p. 13.

3 Hegazy, S., Rahenjat, H., and Hussain, K. Multi-body dynamics in full-vehicle handling analysis. Proc. Instn. Mech. Engrs, Part K: J. Multi-body Dynamics, 213 (k1), 1999, 19-31.

4 Hegazy, S., Rahenjat, H., and Hussain, K. Multi-body dynamics in full-vehicle handling analysis under transient manoeuvre. Vehicle Syst. Dyn., 2000, 34, 1-24.

5 Rahenjat, H. Multi-body dynamics: historical evolution and application. Proc. Instn Mech. Engrs, Part C: J. Mechanical Engineering Science, 2000, 214 (C1), 149173 , special millennium issue.

6 British Standard Automobile Series (BS AU 189), Method of test for steady state cornering behaviour for road vehicles. British Standards Institution, 1983, G-25A-1-G-25A-16.

7 Pacejka, H. B. Tyre and vehicle dynamics, 2002 (Butterworth-Henemann, Oxford, UK) (ISBN 0750651415).

8 Robert, H., Walter, T., Basil, H., Jose, E., and Anthony, J. Experimental investigation of the ground transportation systems (GTS) project for heavy vehicle drag reduction. SAE paper 960907, 1996, pp. 237-258.

9 Hucho, W. H. Designing cars for low drag - state of the art and future potential. Int. J. Vehicle Design, Technol. Adv. Vehicle Design Series, SP3, Impact Aerodyn. Vehicle Design, 1983, 1-8.

10 Khan, Z. A., Deaves, D. M., and Dean, R. B. Use of computational aerodynamics in wind-tunnel tests on motor vehicles. Int. J. Vehicle Design, Technol. Adv. Vehicle Design Series, SP3, Impact Aerodyn. Vehicle Design, 1983, 461-470.

11 Hurst, D. W., Allan, J. W., and Burgin, K. Pressure measurements on a full-scale tractor-trailer combination and comparison with data from wind-tunnel model tests. Int. J. Vehicle Design Technol. Adv. Vehicle Design Series, SP3, Impact Aerodyn. Vehicle Design, 1983, 471-479.
12 Launder, B. E. and Spalding, D. B. Mathematical models of turbulence, 1972 (Academic Press, London).

13 Bakker, E., Pacejka, H. B., and Lidner, L. A new tyre model with an application in vehicle dynamics studies. SAE Paper 890087, 1989.

14 Fiala, E. Seitenkrafte am rollenden luftreifen. VDIZeitschrift, 96, 1964, 973.

15 Shuring, D. J., Pelz, W., and Pottinger, M. G. The BNPS model. An automated implementation of the 'Magic Formula' concept. SAE paper 931909, 1993, pp. 120-130.

16 Blundell, M. V. The modelling and simulation of vehicle handling part 1: analysis methods. Proc. Instn Mech. Engrs, Part K: J. Multi-body Dynamics, 1999, 213 (k2), 130-118.

17 Gear, C. W. Simultaneous numerical solution of differential-algebraic equations. Circuit Theory, 1971, 18, 89-95.

18 Rahnejat, H. Multi-body dynamics: vehicles, machines and mechanisms, 1998 (Professional Engineering Publishing, Bury St Edmunds and London, UK and Society of Automotive Engineers, Warrendale, Pennsylvania, USA).

19 SAE wind tunnel test procedure for trucks and buses, SAE J1252 recommended practice, report of the truck and bus Committee, August 1979.

20 Aerodynamic testing of road vehicles. SAE surface vehicle information, Report J 2071, 1990.

21 Funderburk, R. S. and Carper, H. J. Wind tunnel investigation of an inflatable aerodynamic boattail for tractor-trailers. SAE paper 960908, 1996, pp. 261-267.

22 Watari, A., Tsuchiya, S., and Iwase, H. On the cross-wind sensitivity of the automobile. Proceedings of the 15th FISITA Congress, 1974, pp. 480-487.

23 CFX - 4.2 solver manual, 1997 (AEA Technology, UK).

24 Cogotti, A. Aerodynamic characteristics of car wheels. Int. J. Vehicle Design, Technol. Adv. Vehicle Design Series, SP3, Impact of Aerodyn. Vehicle Design, 1983, 173-196.

\section{APPENDIX}

\section{Notation}

$A_{\mathrm{f}}$

$A_{\mathrm{p}}$

$B$

$C$

$C_{\mathrm{D}}$

$C_{\mathrm{k}}$

$C_{\mathrm{L}}$

$C_{\mathrm{P}}$

$C_{\mathrm{s}}$

$C_{\mathrm{z}}$

$C_{\mathrm{r}}$

$D$

$\mathrm{d} t$

E

$F_{\mathrm{D}}$

$F_{\mathrm{L}}$ projected frontal area

projected plane area

stiffness factor

shape factor

drag coefficient

$k$ th constraint function in a joint

lift coefficient

pressure coefficient

longitudinal tyre stiffness

radial tyre stiffness

rolling resistance moment

coefficient

maximum amplitude factor

integration step size

curvature factor

drag force

lift force 


\begin{tabular}{|c|c|c|c|}
\hline$F_{q}$ & $\begin{array}{l}\text { generalized forces in Euler frame } \\
\text { of reference }\end{array}$ & $V_{\mathrm{c}}$ & $\begin{array}{l}\text { contact patch velocity relative to } \\
\text { road surface }\end{array}$ \\
\hline$F_{x}$ & longitudinal tyre force & $x, y, z$ & displacements in Cartesian \\
\hline$F_{y}$ & lateral tyre force & & coordinates \\
\hline$F_{z}$ & vertical tyre force & $Z_{1}$ & reference head \\
\hline$[\mathbf{J}]$ & jacobian matrix & & \\
\hline K & turbulent kinetic energy & $\alpha$ & slip angle \\
\hline$m$ & number of constraints & $\gamma$ & camber angle \\
\hline$M_{y}$ & rolling resistance moment & $\delta$ & tyre deflection \\
\hline$M_{z}$ & self aligning moment & $\varepsilon$ & dissipation rate \\
\hline$M_{\psi}, M_{\theta}, M_{\phi}$ & rigid momenta & $\lambda$ & Lagrange multiplier \\
\hline$n$ & number of rigid parts & $\mu$ & friction coefficient \\
\hline$P$ & air pressure & $\rho$ & air density \\
\hline$P_{1}$ & reference pressure & $\psi, \theta, \phi$ & Euler angles \\
\hline$q$ & generalized coordinates & & \\
\hline$S$ & longitudinal slip ratio & & \\
\hline$S^{*}$ & critical longitudinal slip ratio & Superscript & \\
\hline$S_{t}$ & cornering stiffness & . & rate of change with time \\
\hline$S_{h}$ & $x$ offset & $\cdot$ & late or Change witul timte \\
\hline$S_{v}$ & $y$ offset & & \\
\hline$t$ & time & Subscripts & \\
\hline$T$ & air temperature & & \\
\hline$u$ & longitudinal velocity & $i j$ & body $i$ relative to body $j$ \\
\hline$U_{1}$ & free stream velocity & $k$ & $k$ th holonomic constraint \\
\hline$v$ & lateral velocity & & function \\
\hline
\end{tabular}

